\title{
GROWTH PERFORMANCE AND POST-HARVEST QUALITY OF GIFT TILAPIA REARED IN TWO DIFFERENT CULTURE SYSTEMS
}

\author{
FARAH FARHANIM MOHD ZIN, NAJAMUDDIN ABDUL BASRI, SUJJAT AL-AZAD, \\ SALEEM MUSTAFA and ROSSITA SHAPAWI* \\ Borneo Marine Research Institute, Universiti Malaysia Sabah, \\ Jalan UMS, 88400, Kota Kinabalu, Sabah \\ *E-mail: rossita@ums.edu.my
}

Accepted 2 May 2020, Published online 30 June 2020

\begin{abstract}
The growth performance, feed utilization, sensory evaluation, proximate and fatty acid composition of Genetically Improved Farmed Tilapia (GIFT) reared in different aquaculture systems (tank and cage culture in pond) were examined in a 126-day feeding trial. Throughout the feeding trial, fish were fed commercial tilapia feed twice a day at $3 \%$ of their body weight. Significantly higher final body weight, weight gain, daily growth rate, viscerosomatic and hepatosomatic indices were yielded in GIFT tilapia cultured in pond than in tank. In contrast, GIFT tilapia cultured in tank showed significantly higher survival rate than GIFT tilapia cultured in pond. Higher positive scores of sensory evaluation test were observed in both treatments, indicating the good acceptance of consumers towards GIFT tilapia. Meanwhile, higher contents of 20:5n-3 and 22:6n-3 of GIFT tilapia fillets from tank culture system than those cultured in cage were mainly influenced by significantly different size of fish and maturity factor during harvest. In general, it can be concluded that the performance of GIFT tilapia reared in pond culture system was better than those in tank culture system with benefits of early harvest and faster growth rate. On the other hand, tank culture system also has its own advantages in terms of higher survival rate and better fatty acid profile.
\end{abstract}

Key words: Aquaculture systems, freshwater fish, GIFT, tilapia, growth performance, sensory quality

\section{INTRODUCTION}

The origin of the Genetically Improved Farmed Tilapia (GIFT) strain of Nile tilapia Oreochromis niloticus was described in detail by Ponzoni et al. (2005) and Nguyen et al. (2007). GIFT tilapia has been disseminated to at least 11 countries in Asia and a fully pedigreed population based on the sixth generation of GIFT was established in Malaysia in 2002 (Gupta \& Acosta, 2004; Ponzoni et al., 2008). The increasing interest in the farming of GIFT strain tilapia is mainly due to its many advantages such as rapid growth rate, high fillet yield, and good disease resistance capability (Dey et al., 2000; Qiang et al., 2012). Traditionally, tilapia has been cultured in earthen ponds under extensive and semi-intensive systems (El-Sayed, 2006). In general, GIFT tilapia was reported to perform well across common farming conditions and environments (Nguyen et al., 2011).

\footnotetext{
* To whom correspondence should be addressed.
}

Even though freshwater aquaculture in Sabah, Malaysia is not growing as rapid as the mariculture sector, it is still considered a very important sector especially in tackling the issue with food security. With the frequent occurrence of harmful algae bloom in the West Coast of Sabah, the local people have to turn to other protein sources which include the freshwater fishes. Therefore, boosting the freshwater aquaculture sector in the West Coast of Sabah is seen as an agenda to be considered seriously by the government. However, the expansion of aquaculture in Malaysia is being increasingly constrained by problems closely linked to the large expanse of land required for intensive aquaculture in pond. Therefore, promotion of urban aquaculture such as using tank culture system is given more attention these days. There are various debates among researches on these ideas. Tank culture production should be able to minimize the impact on degradation of land. While others prefer the traditional way as it maximizing profits to the fish farmers and economically cheaper than the urban 
aquaculture system. Previous researchers have studied the effects of culture systems basically on tank shape and volumes in relation to growth performance of fish (Kolkovski et al., 1995), evaluation of lipid and fatty acid of GIFT tilapia in a semi-intensive systems (Al-Souti \& Claereboudt, 2014), performance of GIFT tilapia in fresh and seawater (Ridha, 2014) and evaluation on GIFT tilapia reared in cages and grown under natural conditions in reservoir (De Silva et al., 2015). However, the performances of the fish in both culture systems have not been adequately investigated to prove the significant eligibility between the current ideas of fish farming in Malaysia. Thus, this study aimed at determining the performances of GIFT tilapia in cage (pond) and tank culture systems including their growth, survival rate and postharvest quality and fatty acids composition.

\section{MATERIALS AND METHODS}

\section{Culture systems}

Two aquaculture systems were tested in the present study, namely tank culture and cage culture in pond. The tank culture and cage culture in pond experiments were conducted at the Borneo Marine Research Institute, Universiti Malaysia Sabah and Tasik Riwak Ranch, Sipitang Sabah, respectively. The experimental tank was ractangular in shape with length $=0.8$ metre, width $=0.8$ metre and depth $=1$ metre; volume $=512$ litre and supplied with aeration system. The cages ( $3 \mathrm{~mm}$ mesh size) were also constructed with the same shape and dimension with the tanks. The cages were placed in an earthen pond measuring 44 x 27 metre, and approximately 2 metre depth with water inlet and outlet fully dependent on the river flow nearby. Water quality assessment on salinity, dissolved oxygen (DO), temperature and $\mathrm{pH}$ was done throughout the trials using YSI handled multiparameter meter (EUTECH PCD650) before every feeding session. Nutrient analysis consist of Nitrate, Nitrite \& Ammonium were tested once in every 2 weeks using Aquamerk Test Kit (Table 2). Meanwhile, plankton samples were collected from the ponds with a plankton net (50 $\mu \mathrm{m}$ mesh size) and fixed with $10 \%$ formalin for identification by using a light microscope (compound and stereo microscope) which was then subjected to various identification sources; books and websites (Cronberg \& Annadotter, 2005; Sardet, 2015).

\section{Feeding trials and performance analysis}

GIFT tilapia juveniles were obtained from the Freshwater Aquaculture Station Marakau Ranau, Sabah. Stocking density was set at 50 fish/tank or cage. The average weight of fish in tanks and cages were $4.52 \pm 0.01 \mathrm{~g}$ and $5.40 \pm 0.30 \mathrm{~g}$, respectively. This slight initial weight difference was due to the different stocking day as a result of distance challenges (different experimental location). GIFT tilapia were hand-fed at $3 \%$ of body weight using floating tilapia feed (Cargill Feed Sdn. Bhd., Malaysia) containing $32 \%$ of crude protein, $4 \%$ of crude fat, $6 \%$ crude fiber and $12 \%$ of moisture. Table 1 shows the fatty acid composition of the commercial feed. Feeding was done in two sessions per day at around 8 am in the morning and at $4 \mathrm{pm}$ in the afternoon. The total length and weight of all the fish were measured every two weeks. Weight gain, daily growth rate (DGR), percentage weight gain, specific growth rate (SGR), survival rate, feed intake, feed conversion ratio (FCR), hepatosomatic index (HSI) and viscerasomatic index (VSI) were calculated using the following formula:

$$
\begin{gathered}
\text { Weight Gain = } \\
\text { Average final weight }- \text { average } \\
\text { initial weight }
\end{gathered}
$$

Daily Growth Rate, DGR = Total weight gain culture days

Percentage Weight Gain $=($ Average final weight Average initial weight)/ (Average initial weight) $\mathrm{x}$ $100 \%$

Specific Growth Rate, SGR = Log (final weight) Log (initial weight) / (Time period [days]) x 100\%

Survival Rate $(\%)=($ Initial number of fish stocked - Mortality)/ (Initial number of fish stocked) x 100\%

Feed Conversion Ratio, FCR $=($ Total weight of dry feed given $(\mathrm{g}) /$ (Total weight gain $(\mathrm{g})$ )

Feed Intake, FI (g) = Total feed intake for 126 days

HSI $(\%)=($ liver weight/fish weight $) \times 100$

VSI $(\%)=($ visceral weight $/$ fish weight $) \times 100$

\section{Fish sample preparation}

The feeding trial was terminated when the fish attained the common market weight which is approximately $250 \mathrm{~g}$. Then a total of 5 fish from each tank and cage were randomly selected and killed in crushed ice for flesh quality attributes evaluation. Another 10 fish were selected and killed using overdose anaesthetic Transmore (NIKA Brand) for fillet proximate and fatty acid analysis. Final weight, final length, fish liver, viscera were measured and fish samples were stored at $-80^{\circ} \mathrm{C}$ for final body proximate analysis and body indices calculation. 
Table 1. Fatty acid composition of commercial tilapia feed

\begin{tabular}{llc}
\hline Type & Fatty acids & Concentration (\%) \\
\hline SFA & C16:0 & $19.66 \pm 0.23$ \\
& C18:0 & $3.44 \pm 0.04$ \\
& TOTAL SFA & $24.78 \pm 2.72$ \\
MUFA & C18:1 n9c & $23.03 \pm 0.19$ \\
& TOTAL MUFA & $25.90 \pm 3.74$ \\
& C18:2 n6c & $32.22 \pm 0.56$ \\
& C18:3 n3 & $3.78 \pm 0.09$ \\
PUFA & C20:5 n3 & $1.86 \pm 0.05$ \\
& C22:2 & $1.22 \pm 0.02$ \\
& C22:6 n3 & $9.25 \pm 0.04$ \\
& TOTAL PUFA & $49.38 \pm 3.87$ \\
& TOTAL UFA & $75.28 \pm 2.64$ \\
& TOTAL UFA/SFA & $3.04 \pm 0.04$ \\
& TOTAL n-3 & $14.89 \pm 0.21$ \\
& TOTAL n-6 & $33.12 \pm 0.59$ \\
& (n-3)/(n-6) & $0.45 \pm 0.10$ \\
\hline
\end{tabular}

Note: (Data expressed as \% of total fatty acids, mean \pm SE). Minor fatty acids (concentration $<1.0 \%$ ) not listed here were $\mathrm{C} 14: 0, \mathrm{C} 15: 0$, C17:0, C20:0, C24:0, C16:1, C18:1 n9t, C20:1, C22:1, C24:1, C18:2 n9t, C20:3 n9t and C20:4 n6. SFA - (Saturated fatty acid), MUFA - (Monounsaturated fatty acid), PUFA - (Polyunsaturated fatty acid, UFA - (Unsaturated fatty acid).

\section{Post-harvest quality attributes}

A five-point hedonic scale were used in evaluating sensory of the GIFT tilapia fillets as described by Eyo (2001). Then 49 untrained panels were provided with questionnaires and evaluated the three parts of post-harvest quality evaluation process:

I. Physical appearance \& freshness of raw GIFT tilapia (whole fish) after harvested which were evaluated based on the appearance, eyes \& gills colour, scales, flesh and odor. Using acceptance test (5-point hedonic scale were used; 1Extremely fresh-like, 2- Fresh-like, 3- Neither fresh nor off-odor detected, 4- Off-odor (rancid) and 5- Extremely off-odor/very rancid).

II. Eating quality of steam GIFT tilapia fillets evaluated based on fillets appearance, texture, odor \& taste by using 5-point hedonic scale of acceptance test (1- Like extremely, 2- Like, 3Neither like nor dislike 4- Dislike and 5- Dislike extremely).

III. Eating quality of steam GIFT tilapia fillets dipped with Asam Pedas gravy and evaluated by using pair-preference model test. Untrained panels chose sample of fillets that they like/most preferred and dislike/least preferred, and then state their comments.

\section{Chemical analysis}

Crude protein, crude lipid and moisture were determined with the following standard methods of Association of Official Analytical Chemistry (AOAC, 2005). Fatty acid analysis was conducted by analysing the fatty acid methyl ester from the crude extract in a gas chromatography (Shimadzu GC-2010, Shimadzu Corporation, Kyoto, Japan), equipped with flame ionization detector and an auto injector. Capillary column (60 m x $0.25 \mathrm{~mm}$ ID; BPX70 column, SGE, Australia) was used to separate the esters. Peaks were identified by comparing their retention times with commercially known mixtures of 37 components FAME MIX Standard (Supelco ${ }^{\mathrm{TM}}$ 37 Component FAME mix, Supelco Inc., Bellefonte, USA).

\section{Statistical analysis}

All the results were expressed as mean \pm standard error (SE). Data were compared between the culture systems by Student's t-test at $5 \%$ significance level using the SPSS statistical package program (SPSS 17.0, SPSS Inc., Chicago, Illinois, USA). Mann-Whitney U test were subjected to hedonic scale test and Chi-square test on pairedpreference test at 5\% significance level.

\section{RESULTS}

\section{Water quality and plankton composition}

Overall, the water quality and nutrient content in both culture systems were considered to be in a suitable range and favourable for aquaculture practice. The temperature, dissolved oxygen and $\mathrm{pH}$ ranged from $28.04-31.45^{\circ} \mathrm{C}, 5.38-6.59 \mathrm{ppm}$ and 5.45-7.05, respectively. Meanwhile, nitrate was not detected in both culture systems. Nitrite and ammonia ranged from $0.00-0.01 \mathrm{mg} / \mathrm{L} \mathrm{NO}$ and $0.00-0.25 \mathrm{mg} / \mathrm{L} \mathrm{NH}$, respectively (Table 2). The plankton composition was dominated by several zooplankton and phytoplankton species i.e: river shrimp (Caridae sp.), water fleas (Daphnia sp.), Scenedesmus sp. and Chlorella sp..

\section{Growth performance}

GIFT cultured in cage had better MWT, DGR, SGR and FCR (360.06 g, $2.86 \mathrm{~g} \mathrm{fish}^{-1}$ day $^{-1}, 3.35 \%$ day $^{-1}$ and 1.06, respectively) than GIFT tilapia cultured in tank (288.37 g, $2.29 \mathrm{~g} \mathrm{fish}^{-1}$ day $^{-1}, 3.31 \%$ day $^{-1}$ and 1.41 , respectively). In contrast, GIFT tilapia cultured in tank had significantly higher survival rate $(100 \%)$ compared to those cultured in cage $(94 \%)$. Significantly higher values $(\mathrm{P}<0.05)$ of VSI and HSI of GIFT tilapia reared in cage than in tank were also observed (Table 3). Figure 1 shows the exponential increase of weight gain of tilapia GIFT cultured in both systems, with higher $\mathrm{R}^{2}$ value in pond culture system. 
Table 2. Water quality parameters recorded throughout the feeding trial

\begin{tabular}{lcc}
\hline \multirow{2}{*}{ Water parameters } & \multicolumn{2}{c}{ Range } \\
\cline { 2 - 3 } & Tank & Cage (Pond) \\
\hline Temperature $\left({ }^{\circ} \mathrm{C}\right)$ & $28.04 \pm 0.17^{\mathrm{a}}$ & $31.45 \pm 0.93^{\mathrm{a}}$ \\
Dissolved oxygen $(\mathrm{ppm})$ & $6.59 \pm 0.18^{\mathrm{a}}$ & $5.38 \pm 0.13^{\mathrm{a}}$ \\
$\mathrm{pH}$ & $5.45 \pm 0.03^{\mathrm{a}}$ & $7.05 \pm 0.41^{\mathrm{a}}$ \\
Nitrate $(\mathrm{mg} / \mathrm{L})$ & Not detected & Not detected \\
Nitrite $(\mathrm{mg} / \mathrm{L})$ & $0.00 \pm 0.00^{\mathrm{a}}$ & $0.01 \pm 0.01^{\mathrm{a}}$ \\
Ammonium $(\mathrm{mg} / \mathrm{L})$ & $0.25 \pm 0.14^{\mathrm{a}}$ & $0.00 \pm 0.00^{\mathrm{b}}$ \\
\hline
\end{tabular}

Note: Means \pm SE (standard error) in horizontal followed by the same letter are not significantly different $(P>0.05)$ from each other.

Table 3. Growth performance of GIFT tilapia in different culture systems

\begin{tabular}{lcc}
\hline Parameters & Tank culture system & Cage culture system \\
\hline Mean initial body weight $(\mathrm{g})$ & $4.53 \pm 0.51^{\mathrm{a}}$ & $5.40 \pm 0.80^{\mathrm{a}}$ \\
Mean final body weight $(\mathrm{g})$ & $292.90 \pm 16.32^{\mathrm{a}}$ & $366.06 \pm 6.94^{\mathrm{b}}$ \\
Mean initial total length (cm) & $6.35 \pm 0.10^{\mathrm{a}}$ & $6.52 \pm 0.03^{\mathrm{a}}$ \\
Mean final total length (cm) & $21.78 \pm 1.18^{\mathrm{a}}$ & $22.45 \pm 0.20^{\mathrm{a}}$ \\
Mean weight gain (MWT), (g) & $288.37 \pm 7.03^{\mathrm{a}}$ & $360.06 \pm 5.36^{\mathrm{b}}$ \\
Daily growth rate (DGR), (g fish ${ }^{-1}$ day $\left.^{-1}\right)$ & $2.29 \pm 0.13^{\mathrm{a}}$ & $2.86 \pm 0.06^{\mathrm{b}}$ \\
Specific growth rate (SGR), $\left(\%\right.$ day $\left.^{-1}\right)$ & $3.31 \pm 0.07^{\mathrm{a}}$ & $3.35 \pm 0.05^{\mathrm{a}}$ \\
Total feed intake (g) per culture system & $100716.26 \pm 88.75^{\mathrm{a}}$ & $120705.48 \pm 54.44^{\mathrm{a}}$ \\
Feed conversion ratio (FCR) & $1.41 \pm 1.59^{\mathrm{a}}$ & $1.06 \pm 0.20^{\mathrm{a}}$ \\
Survival (\%) & $100.00 \pm 0.00^{\mathrm{a}}$ & $94.00 \pm 1.16^{\mathrm{b}}$ \\
VSI $\%)$ & $5.38 \pm 1.72^{\mathrm{a}}$ & $9.16 \pm 0.20^{\mathrm{b}}$ \\
HSI $\%)$ & $1.26 \pm 0.06^{\mathrm{a}}$ & $2.50 \pm 0.44^{\mathrm{b}}$ \\
\hline
\end{tabular}

Note: Means \pm SE (standard error) in horizontal followed by the same letter are not significantly different $(p>0.05)$ from each other.

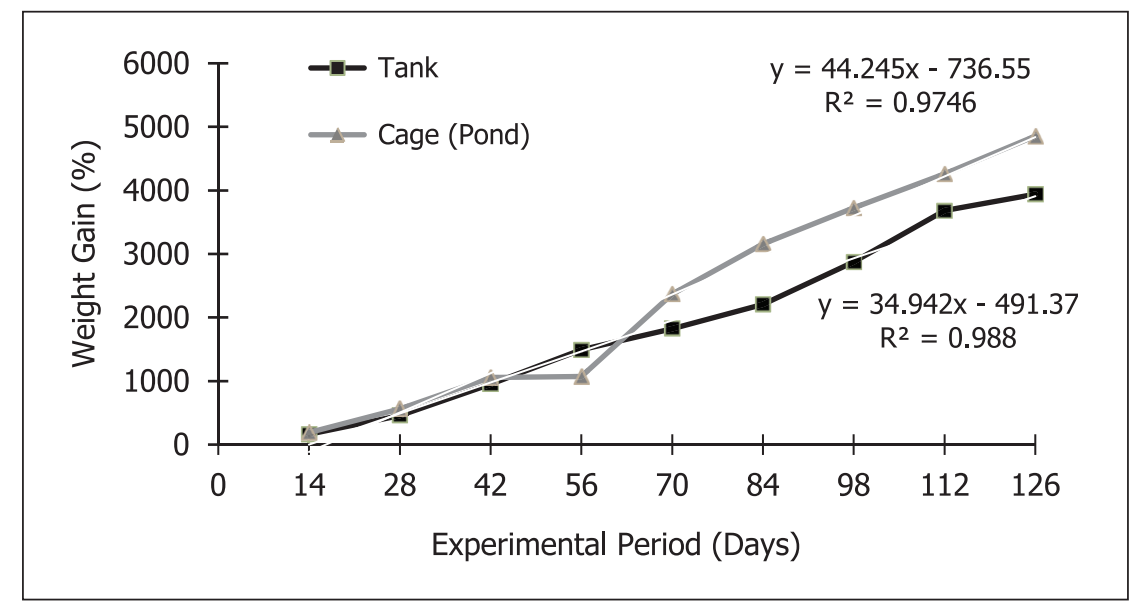

Fig. 1. Weight gain (\%) over time of tilapia GIFT in both culture systems.

\section{Sensory evaluation}

The mean scores for physical evaluation of raw whole-fish and sensory evaluation of steamed fillet are presented in Table 4. Based on physical evaluation, appearance (3.06-4.71), odor (3.06-
3.87) and overall acceptability (3.67-3.87) were significantly influenced by the culture system. However, freshness value (3.46) was better for wholefish produced from tank culture than those from cage (odor, 3.46; overall acceptability, 3.67). Except 
Table 4. Physical evaluation of raw whole-fish and steamed GIFT fillets by using hedonic 5 scale scores

\begin{tabular}{lcc}
\hline \multirow{2}{*}{ Sensory attributesof raw whole-fish } & \multicolumn{2}{c}{ Acceptance scores for each cultures } \\
\cline { 2 - 3 } & Tank & Cage (Pond) \\
\hline Appearance & $3.06 \pm 1.06 \mathrm{E}$ & $4.71 \pm 0.24 \mathrm{G}$ \\
Odor & $3.87 \pm 0.55 \mathrm{E}$ & $3.46 \pm 1.03 \mathrm{G}$ \\
Freshness & $3.46 \pm 0.49 \mathrm{E}$ & $3.06 \pm 0.19 \mathrm{E}$ \\
Overall Acceptability & $3.87 \pm 1.08 \mathrm{E}$ & $3.67 \pm 0.73 \mathrm{G}$ \\
\hline & Sensory attributes of steamed GIFT fillet & $3.53 \pm 0.27 \mathrm{E}$ \\
\hline Appearance & $3.33 \pm 0.13 \mathrm{E}$ & $4.01 \pm 0.14 \mathrm{G}$ \\
Odor & $3.34 \pm 0.43 \mathrm{E}$ & $4.42 \pm 0.72 \mathrm{E}$ \\
Texture & $4.62 \pm 0.36 \mathrm{E}$ & $4.35 \pm 0.24 \mathrm{G}$ \\
Taste & $3.81 \pm 0.11 \mathrm{E}$ & $3.74 \pm 0.01 \mathrm{E}$ \\
Overall acceptability & $3.46 \pm 0.09 \mathrm{E}$ & \\
\hline
\end{tabular}

Note: Means were calculated from panellist responses $(n=49)$ for each attribute. Mean \pm SE in horizontal followed by the same letter are not significantly different $(p>0.05)$ from each other.

Table 5. Proximate composition (\% wet weight) of GIFT tilapia fillet cultured in two different systems

\begin{tabular}{|c|c|c|c|}
\hline \multirow{2}{*}{ Means } & \multicolumn{2}{|c|}{ Culture Systems } & \multirow{2}{*}{ P-value } \\
\hline & Tank & Cage (Pond) & \\
\hline Moisture & $79.10 \pm 0.34 \mathrm{E}$ & $78.65 \pm 0.45 E$ & 0.57 \\
\hline Crude Protein & $15.90 \pm 0.87 \mathrm{E}$ & $15.35 \pm 2.56 \mathrm{E}$ & 0.12 \\
\hline Crude Lipid & $1.54 \pm 0.73 E$ & $3.35 \pm 2.39 E$ & 0.83 \\
\hline Fibre & $0.12 \pm 0.08 \mathrm{E}$ & $0.21 \pm 0.39 E$ & 0.73 \\
\hline Ash & $1.45 \pm 0.66 \mathrm{E}$ & $1.05 \pm 0.56 \mathrm{G}$ & 0.04 \\
\hline
\end{tabular}

Note: Values \pm SE in the same row with the same superscript are not significantly different $(P>0.05)$.

for odor (3.34, tank culture; 4.01, cage culture) and taste (3.81, tank culture; 4.35 , cage culture); appearance (3.33, tank culture; 3.53 , cage culture), texture (4.62, tank culture; 4.42, cage culture) and overall acceptability (3.46, tank culture; 3.74 , cage culture) of GIFT tilapia fillet were not affected by the culture system. Nevertheless, numerically higher scores were obtained for appearance, odor, taste and overall acceptability for GIFT tilapia fillet from cage culture in the pond.

\section{Proximate and fatty acid composition}

Except for crude ash content, the proximate composition of GIFT tilapia fillet from the two culture systems was not significantly different from each other (Table 5). Moisture, crude protein, crude lipid, crude fibre and crude ash ranged from 78.65$79.10 \%, 15.35-15.90 \%, 1.54-3.35 \%, 0.12-0.21 \%$ and $1.05-1.45 \%$, respectively.

Of the saturated fatty acids (SFA), palmitic acid (C16:0) had the highest proportion, while oleic acid (C18:1n-9) was the main monounsaturated fatty acid (MUFA) and polyunsaturated fatty acid (PUFA) was also detected in the form of docosahexaenoic acid (DHA). However, total of
SFA, MUFA and PUFA were not significantly different between the culture systems. Interestingly, significantly higher concentration of 24:0, 22:1n9, 22:6n-3 and (n-3)/(n-6) of FA in fillets of GIFT tilapia cultured in tank than in cage was observed. Contradictly, significantly higher concentration of linoleic acid 18:2n-6 (19.53 $\pm 0.05 \%)$ of GIFT tilapia fillet cultured in cage than those in tank $(16.57 \pm 0.12)$ (Table 6).

\section{DISCUSSION}

Superior growth performance of GIFT tilapia in cage compared to tank culture system was yielded in the present study. Fish cultured in cages have the advantages of having excess to natural food in the pond such as shrimp, small fish and macroplanktons. Besides, large volume of water exchange was also occurred in cage culture system. The water in pond observed in this study was dominated by Caridae sp., Daphnia sp., Scenedesmus sp. and Chlorella sp. which were common aquatic organisms found in freshwater bodies (Beniga \& Circa, 1997; Hussain et al., 2000; Mather \& Nandlal, 2000). The lower 
Table 6. Mean fatty acids composition of fillet GIFT tilapia reared in different culture systems

\begin{tabular}{llcc}
\hline \multirow{2}{*}{ Type } & Fatty acid & \multicolumn{2}{c}{ Concentration $(\%)$} \\
\cline { 3 - 4 } & & Tank culture system & Cage culture system \\
\hline SFA & C14:0 & $1.42 \pm 0.05 \mathrm{E}$ & $1.72 \pm 0.03 \mathrm{E}$ \\
& C16:0 & $19.11 \pm 0.19 \mathrm{E}$ & $21.07 \pm 0.27 \mathrm{E}$ \\
& C18:0 & $4.43 \pm 0.28 \mathrm{E}$ & $4.25 \pm 0.03 \mathrm{E}$ \\
C24:0 & $1.49 \pm 0.18 \mathrm{E}$ & $0.74 \pm 0.03 \mathrm{G}$ \\
MUFA & $27.39 \pm 1.15 \mathrm{E}$ & $28.86 \pm 1.88 \mathrm{E}$ \\
& TOTAL SFA & $3.18 \pm 0.23 \mathrm{E}$ & $3.59 \pm 0.38 \mathrm{E}$ \\
& C16:1 & $21.52 \pm 0.33 \mathrm{E}$ & $26.25 \pm 0.03 \mathrm{E}$ \\
PUFA & C18:1 n9c & $0.85 \pm 0.11 \mathrm{E}$ & $1.01 \pm 0.03 \mathrm{E}$ \\
& C20:1 & $6.70 \pm 0.13 \mathrm{E}$ & $0.16 \pm 0.08 \mathrm{G}$ \\
& C22:1 n9 & $32.78 \pm 1.90 \mathrm{E}$ & $31.36 \pm 1.03 \mathrm{E}$ \\
& TOTAL MUFA & $20.31 \pm 0.09 \mathrm{E}$ & $22.79 \pm 0.12 \mathrm{G}$ \\
& C18:2 & $0.98 \pm 0.05 \mathrm{E}$ & $1.17 \pm 0.20 \mathrm{E}$ \\
& C18:3 n6 & $0.61 \pm 0.00 \mathrm{E}$ & $1.36 \pm 0.06 \mathrm{E}$ \\
& C18:3 n3 & Nd & $1.74 \pm 0.03 \mathrm{E}$ \\
& C20:3 n6 & $6.70 \pm 0.13 \mathrm{E}$ & $4.12 \pm 0.14 \mathrm{E}$ \\
& C20:4 n6 & $0.29 \pm 0.09 \mathrm{E}$ & $0.16 \pm 0.16 \mathrm{E}$ \\
& C20:5 n3 & $14.59 \pm 0.23 \mathrm{E}$ & $7.88 \pm 0.17 \mathrm{G}$ \\
& C22:6 n3 & $39.83 \pm 2.15 \mathrm{E}$ & $39.78 \pm 2.05 \mathrm{E}$ \\
& TOTAL PUFA & $72.61 \pm 1.55 \mathrm{E}$ & $71.14 \pm 1.98 \mathrm{E}$ \\
& UFA & $2.65 \pm 0.07 \mathrm{E}$ & $2.47 \pm 0.02 \mathrm{E}$ \\
& UFA/SFA & $15.49 \pm 1.39 \mathrm{E}$ & $9.40 \pm 0.75 \mathrm{E}$ \\
& n-3 PUFA & $19.92 \pm 0.19 \mathrm{E}$ & $26.56 \pm 0.35 \mathrm{E}$ \\
& (n-6 PUFA & $0.78 \pm 0.09 \mathrm{E}$ & $0.35 \pm 0.05 \mathrm{G}$ \\
\hline & & &
\end{tabular}

Note: Percentage means in horizontal followed by the same letter are not significantly different $(p>0.05)$ from each other. Minor fatty acids (concentration < 1.0\%) not listed here except for EPA were C15:0, C17:0, C21:0, c24:1 and C22:2. SFA - (Saturated fatty acid), MUFA - (Monounsaturated fatty acid), PUFA - (Polyunsaturated fatty acid, UFA - (Unsaturated fatty acid)).

growth performance of GIFT tilapia in tank culture system could have also been caused by several other factors such as behavioural interaction, competition for food and living space; and increased stress (Diana et al., 2004; Chakraborty \& Banerjee, 2010).

Eventhough the survival rate of GIFT tilapia cultured in tank was significantly higher than in cage, the survival rate of GIFT tilapia in the present study was considered very high, indicating good health of the cultured fish in both culture systems. Factors such as quality such as water temperature, dissolved oxygen concentration, $\mathrm{pH}$, and waste in the culture system might have some influence (DeLong et al., 2009). However, in the present study, the water quality parameters in both systems were no differed that much. The FCR value was better in GIFT tilapia cultured in pond than those in GIFT tilapia cultured in tank even though the feed intake was insignificant between both culture systems. The better FCR value of tilapia reared in the pond was also partly influenced by the consumption of natural food available in the pond. In the present study, the FCR of GIFT tilapia in tank was relatively better than FCR observed in previous studies; 1.76 (Luo et al., 2011), 1.57-1.74 (Luo et al., 2012) and 1.42-1.46 (Ridha, 2014). The HSI and VSI of GIFT tilapia in the present study increased with the increase of fish size and appeared to be in the normal range of reported HSI and VSI of other tilapia strain (Ochang, 2011; Ada \& Ayotunde, 2013; Ighwela et al., 2014).

In general, higher positive scores were obtained for fillet of fish from both culture systems, indicating the acceptance of consumers toward GIFT tilapia. Other similar finding claimed that the sensory attributes of GIFT fell within the range of highly acceptable flesh (Ponzoni et al., 2008). Nevertheless, as expected, pond culture system produced raw whole fish with lower score of odor as compared to those from tank culture, which affected the overall acceptability of consumers. Researchers stated that tilapia can absorb the flavour from the water it was raised in which associated with blooms of blue-green algae and microbes presence in pond ecosystem (Bett \& Dionigi, 1997; Josupeit, 2005; Che Rohani et al., 2009) and differences in chemical composition of fish could also influence postharvest processing and storage techniques (Musara et al., 2018). Moreover, algae blooms can produce geosmin and 2-methyl-isoborneol (MIB) which impart muddy, musty flavour to freshwater fish (Che Rohani et al., 2009), thus triggering the presence of muddy taste in fillets of tilapia raised in earthen pond. Fortunately, the odor can be 
eliminated by practicing "flush-period" such as washing in supernatant of banana (Musa sp.) (Mohsin et al., 1999), salt solution (Che Rohani et al., 1995) and 4\% acetic acid (El-Sahn et al., 1990) of the fish prior to harvest. Interestingly, the score for overall acceptability of GIFT tilapia fillets from the pond was better than those raised in tank, indicating that cooking process can play a significant role in improving the sensory attributes of the farmed fish.

In the present study, the culture system appeared to have little influence on the proximate composition of GIFT tilapia fillet. The significantly higher ash content of GIFT tilapia cultured in tank $(1.45 \pm 0.66 \%)$ compared to the GIFT tilapia reared in pond $(1.05 \pm 0.56 \%)$ was also observed in the previous study where crude ash of fillet GIFT tilapia reared in tank (1.7-4.3\%) was relatively higher than the cage-pond culture system (0.88-1.15\%) (Zenebe et al., 1988; Ng \& Hanim, 2007; De Silva et al., 2015).

In general, a better profile of fatty acid composition was observed in GIFT tilapia cultured in tank compared to pond culture systems. The individual fatty acid concentration varied between both culture systems, and as expected the levels of eicosapentaenoic acids (EPA, 20:5n-3) and docosahexaenoic acids (DHA, 22:6n-3) in GIFT fillets were lower than many marine fish species, but they were consistent with the results reported by Bahurmiz and $\mathrm{Ng}$ (2007), De Souza et al. (2007) and Ponzoni et al. (2008). Despite of the less type of fatty acids found in GIFT tilapia fillets cultured in tank compared to the GIFT tilapia cultured in pond, a higher content of total MUFA and total PUFA concentration was observed. The most common fatty acids in both culture systems were 16:0, 18:1n-9, 18:2n-6 and 22:6n-3. Similar studies performed on tropical (Clement \& Lovell, 1994) and temperate (Ahlgren et al., 1994) freshwater fishes showed the dominance of these fatty acids in the tissue of fish. Overall, the results of fatty acid concentration were consistent with the results reported for tilapia in tank culture system (Karapanagiotidis et al., 2006; Molnar et al., 2012; Ma et al., 2015) and in pond culture systems (Ponzoni et al., 2008; Nguyen et al., 2010). Some of the GIFT tilapia reared in pond were observed to have spawned during the experimental period (GIFT tilapia fingerlings were noticed nearby the cage during feeding time). Tilapia raised in pond with good growth condition tend to reach sexual maturity at a smaller size of $150 \mathrm{~g}$ to $200 \mathrm{~g}$ and younger age than in an intensive or tank culture systems (Popma \& Masser, 1999; Nandhal \& Pickering, 2004). In the present study, there were about $68 \%$ of the fish harvested at the end of the trial in the pond were weighed more than $300 \mathrm{~g}$ which means about half of stocked GIFT tilapia had reached their maturity. Therefore, the differences in UFAs of GIFT tilapia might be also influenced by the different size of fish at harvest. As the GIFT tilapia cultured in pond have higher growth rate, the fish tend to have larger (older) body size that caused them to have higher level of fat than smaller size fish (Toppe et al., 2006). These alteration might also cause variation in the state of development of gonad and spawning of fish (Caponio et al., 2004; Alemu et al., 2013). Spawning activity of the fish could trench their fat reserves, thereby contributing to the fatty acids variability and low tissue lipids (Osibona, 2011). The fats accumulation during spawning might altered the fatty acids content in GIFT tilapia fillets reared in pond culture systems.

Other than that, FA ratios (n-3)/ (n-6) and UFA/ SFA showed important information concerning the yielded food product. According to Simopoulos (2002), for food to be considered healthy, the ratios must be smaller than 4.0 and greater than 0.4 , respectively. In the present study, the (n-3)/ (n-6) and UFA/SFA ratios in the tilapia fillets were within this range for both culture systems. However, an arduous comparison among studies is impossible as fatty acid composition also stated to be depending on other factors such as stock origin, species habitat, life stage, nutritional history of experiment fish, duration of experiment, gender of fish and reproductive cycle (Ackman, 1982; Ackman, 1989; Saito et al., 1999; Ng \& Chong, 2004; Ponzoni et al., 2008).

\section{CONCLUSION}

In general, it can be concluded that the performance of GIFT tilapia reared in pond culture system was better than those in tank culture system with benefits of early harvest and faster growth rate. On the other hand, tank culture system also has its own advantages in producing promising marketable product which has higher survival rate and better fatty acids profile. Therefore, findings from the present study indicated that both culture sytems are feasible to be practiced in Malaysia depending on the farm's objective and availability of culture facility.

\section{ACKNOWLEDGEMENTS}

This study was supported by a Knowledge Transfer Programme research grant (AM00046) from Ministry of Higher Education, Malaysia. We would like to thank Freshwater Aquaculture Station Marakau Ranau, Sabah for providing us the fingerlings of GIFT tilapia, Tasik Riwak Ranch Sdn. Bhd, Sipitang for providing facilities (pond) during experimental 
period and also the staff of Marine Fish Hatchery of Borneo Marine Research Institute for their technical assistance throughout this study.

\section{REFERENCES}

Ackman, R.G. 1982. Fatty acid composition in fish oil. In: Nutritional evaluation of long-chain fatty acids in fish oil. S.M. Barlow and M.E. Stansby (Eds.). New York, NY: Academic Press. pp. 25-28.

Ackman, R.G. 1989. Nutritional composition of fats in sea foods. Progress in Food \& Nutrition Science, 13(3-4): 161-289.

Ada, F.B. \& Ayotunde, E.O. 2013. Gonado-hepatosomatic index of Oreochromis niloticus sub adults exposed to some herbicides. International Journal of Aquaculture, 3(11): 49-54. doi: 10.5376/ija.2013.03.0011

Ahlgren, G., Blomqvist, P., Boberg, M. \& Gustafsson, I.B. 1994. Fatty acid content of the dorsal muscle - an indicator of fat quality in freshwater fish. Journal of Fish Biology, 45(1): 131-157. doi: 10.1111/j.1095-8649.1994. tb01292.x

Alemu, L.A., Melese, A.Y. \& Gulelat, D.H. 2013. Effect of endogenous factors on proximate composition of Nile Tilapia (Oreochromis niloticus L.) fillet from Lake Zeway. American Journal of Research Communication, 1(11): 405-410.

Al-Souti, A. \& Claereboudt, M. 2014. Total lipid and fatty acid content of Tilapia (GIFT strain) grown in a semi-intensive system: A descriptive view. Research in Health and Nutrition, 2(2): 13-19.

Association of Official Analytical Chemists. 2005. Official methods of analysis: Association of Official Analytical Chemists. Gaithersburg, USA: AOAC International Press.

Bahurmiz, O.M. \& Ng, W.K. 2007. Effects of dietary palm oil source on growth, tissue fatty acid composition and nutrient digestibility of red tilapia, Oreochromis niloticus sp. raised from stocking to marketable size. Aquaculture, 262(2-4): 382-392. doi: 10.1016/j.aquaculture. 2006.11 .023

Beniga, Z.M. \& Circa, A.V. 1997. Growth evaluation of genetically improved Nile tilapia (Oreochromis niloticus L.) in floating net cages in Lake Sebu, South Cotabato, The Philippines. In: Proceedings of the Fourth International Symposium on Tilapia in Aquaculture. K. Fitzsimmons (Ed.). Orlando, Florida, USA. pp. 116-126.
Bett, K.L. \& Dionigi, C.P. 1997. Detecting seafood off-flavors: Limitations of sensory evaluation. Food Technology, 51(8): 70-81.

Caponio, F., Lestingi, A., Summo C., Bilancia, M.T. \& Laudadio, V. 2004. Chemical characteristics and lipid fraction quality of sardines (Sardina pilchardus W.): Influence of sex and length. Journal of Applied Ichthyology, 20(6): 530-535. doi: 10.1111/j.1439-0426.2004.00611.x

Chakraborty, S. \& Banerjee, S. 2010. Effect of stocking density on monosex Nile tilapia growth during pond culture in India. World Academy of Science, Engineering and Technology, 4(8): 1231-1235.

Che Rohani, A., Indon, A. \& Yunus, J.M. 1995. Processing of surimi from freshwater fish Tilapia. Journal of Tropical Agriculture and Food Science, 23(2): 183-190.

Che Rohani, A., Normah, O., Zahrah, T., Che Utama, C. \& Saadiah, I. 2009. Quality of fish fillet from pond-raised red tilapia and its utilisation in the development of value added product. Journal of Tropical Agriculture and Food Science, 37(2): 153-161.

Clement, S. \& Lovell, R.T. 1994. Comparison of processing yield and nutrient composition of Nile tilapia (Oreochromis niloticus) and catfish (Ictalurus punctatus). Aquaculture, 119(2-3): 299-310. doi: 10.1016/0044-8486(94)90184-8

Cronberg, G. \& Annadotter, H. 2006. Manual on aquatic cyanobacteria: A photo guide and a synopsis of their toxicology. Copenhagen, Denmark: ISSHA Publication.

Diana, J.S., Yi, Y. \& Lin, C.K. 2004. Stocking densities and fertilization regimes for Nile tilapia (Oreochromis niloticus) production in ponds with supplemental feeding. In: Proceedings of the Sixth International Symposium on Tilapia in Aquaculture. R., Bolivar, G., Mair and K., Fitzsimmons (Eds.). Manila, Philippines. pp. 487-499.

De Silva, M.P.K.S.K., Senaraarachchi, W.A.R.K. \& Liyanage, N.P.P. 2015. Evaluation of sensory and proximate properties of reservoir grown tilapia (Oreochromis niloticus) and cage cultured genetically improved farm tilapia (GIFT). International Journal of Fisheries and Aquatic Studies, 2(4): 10-13.

DeLong, D.P., Lasordo, T.M. \& Rakocy, J.E. 2009. Tank culture of tilapia. Stoneville, MS, USA: Southern Regional Aquaculture Center (SRAC) Publication No. 282. 
De Souza, N.E., Matsushita, M., De Oliveria, C.C., Franco, M.R.B. \& Visentainer, J.B. 2007. Manipulation of fatty acid composition of Nile tilapia (Oreochromis niloticus) fillets with flaxseed oil. Journal of Science of Food and Agriculture, 87(9): 1677-1681. doi: 10.1002/ jsfa. 2877

Dey, M.M., Eknath, A.E., Sifa, L., Hussain, M.G., Thien, T.M., Hao, N.V., Aypa, S. \& Pongthana, N. 2000. Performance and nature of genetically improved farmed tilapia: A bioeconomic analysis. Aquaculture Economics and Management, 4(1-2): 85-103. doi: 10.080/1365730000 9380262

El-Sahn, M.A., Youssef, A.M. \& Moharram, Y.G. 1990. Edibleproducts from pelagic bissaria (Atherina mochon) fish. Nahrung, 34(1): 47-52.

El-Sayed, A.M. 2006. Tilapia culture. London, United Kingdom: CABI Publishing. 277pp.

Eyo, A. 2001. Fish processing technology in the tropics. New Bussa. National Institute for Freshwater Fisheries Research, Nigeria. Pp $37-$ 39.

Folch, J., Less, M. \& Stanley, H.S. 1957. A simple method for the isolation and purification of total lipids from animal tissues. The Journal of Biochemical Chemistry 226(1): 497-509.

Gupta, M.V. \& Acosta, B.O. 2004. From drawing board to dining table: The success story of the GIFT project. NAGA World Fish Center Quarterly, 27: 4-14.

Haque, M.R., Islam, M.A., Abdul Wahab, M., Enamul-Hoq, M., Mojibar-Rahman, M. \& Azim, E. 2016. Evaluation of production performance and profitability of hybrid red tilapia and genetically improved farmed tilapia (GIFT) strains in the carbon/nitrogen controlled periphyton-based $(\mathrm{C} / \mathrm{N}-\mathrm{CP})$ on-farm prawn culture system in Bangladesh. Aquaculture Reports, 4: 101-111.

Hussain, M.G., Kohinoor, A.H.M., Islam, M.S., Hossain, M.A., Dey, M.M. \& Mazid, M.A. 2000. Growth and production performance of GIFT strain of Nile tilapia, Oreochromis niloticus L., in ponds and cages under different farming conditions in Bangladesh. Journal of Aquaculture in the Tropics, 15(3): 273-280.

Ighwela, K.A., Ahmad, A. \& Abol-Munafi, A.B. 2014. The selection of viscerosomatic and hepatosomatic indices for the measurement and analysis of Oreochromis niloticus condition fed with varying dietary maltose levels. International Journal of Fauna and Biological Studies, 1(3): 18-20.
Karapanagiotidis, I.T., Bell, M.V., Little, D.C., Yakupitiyage, A. \& Rakshit, S.K. 2006. Polyunsaturated fatty acid content of wild and farmed tilapias in Thailand: Effect of aquaculture practices and implication for human nutrition. Journal of Agriculture and Food Chemistry, 54(12): 4304-4310.

Kolkovski, S., Tandler, A., Kissil, W. \& Gertler, A. 1995. The effect of dietary exogenous digestive enzymes on ingestion, assimilation, growth and survival of gilthead seabream (Sparus aurata) larvae. Fish Physiology Biochemstry, 12(3): 203-209. doi: 10.1007/BF00004368

Luo, Z., Liu, C-X. \& Wen, H. 2012. Effect of dietary fish meal replacement by canola meal on growth performance and hepatic intermediary metabolism of Genetically Improved Farmed Tilapia strain of Nile tilapia, Oreochromis niloticus, reared in fresh water. Journal of the Aquaculture Society, 43(5): 670-678. doi: 10.1111/j.1749-7345.2012.00601.x

Luo, Z., Tan, X-Y., Liu, X-J. \& Wen, H. 2011. Effect of dietary betaine levels on growth performance and hepatic intermediary metabolism of GIFT strain of Nile tilapia Oreochromis niloticus reared in freshwater. Aquaculture Nutrition, 17(4): 361-367. doi: 10.1111/j.1365-2095.2010. 00805.x

Ma, X., Qiang, J., He, J., Gabriel, N. \& Xu, P. 2015. Changes in the physiological parameters, fatty acid metabolism, and SCD activity and expression in juvenile GIFt tilapia (Oreochromis niloticus) reared at three different temperatures. Fish Physiology and Biochemistry, 41(4): 937950. doi: 10.1007/s10695-015-0059-4.

Mather, P.B. \& Nandlal, S. 2000. Progress towards providing Fijian farmers with a better tilapia strain: evaluation of the GIFT fish in Fiji. NAGA, 23(4): 46-49.

Mohsin, M., Jamilah, B. \& Selamat, J. 1999. The effects on colour, texture and sensory attributes achieved by washing black tilapia flesh with a banana leaf ash solution. International Journal of Food Science Technology, 34(4): 350-363. doi: 10.1046/j.1365-2621.1999.00281.x

Molnar, T., Biro, J., Hancz, C., Romvari, R., Varga, D. \& Horn, P. 2012. Fatty acid profile of fillet, liver and mesenteric fat intilapia (Oreochromis niloticus) fed vegetable oil supplementation in the finishing period of fattening. Archiv fur Tierzucht, 55(2): 194-205. doi: 10.5194/aab-55194-2012. 
Musara, C., Jim, F. \& Garamumhango, P. 2017. Comparative Analysis of Nutritional Value of Oreochromis niloticus (Linnaeus), Nile Tilapia, Meat from Three Different Ecosystems. Journal of Food Quality, Article ID 6714347, 1-8. https://doi.org/10.1155/2017/6714347.

Nandlal, S. \& Pickering, T. 2004. Tilapia fish farming in Pacific Island countries: Tilapia grow-out in ponds (Volume 2). Noumea, New Caledonia: Secretariat of the Pacific Community. pp 50.

Ng, W.K. \& Hanim, R. 2007. Performance of genetically improved Nile tilapia compared with red hybrid tilapia fed diets containing two protein levels. Aquaculture Research, 38(9): 965-972. doi: 10.1111/j.1365-2109.2007. 01758.x

Ng, W.K. \& Chong, C.Y. 2004. An overview of lipid nutrition with emphasis on alternative lipid sources in tilapia feeds. In: Proceedings of the Sixth International Symposium on Tilapia in Aquaculture. R.G. Bolivar, G.C. Mair \& K. Fitzsimmons (Eds.). (pp. 241-248). Manila, Philippines: Bureau of Fisheries \& Aquatic Resources.

Nguyen, N.H., Khaw, H.L., Ponzoni, R.W., Hamzah, A. \& Kamaruzzaman, K. 2007. Can sexual dimorphism and body shape be altered in Nile tilapia (Oreochromis niloticus) by genetic means? Aquaculture, 272(S1): S38-S46. doi: 10.1016/j.aquaculture.2007.08.013

Nguyen, N.H., Ponzoni, R.W., Yee, H., Abu-Bakar, K., Hamzah, A. \& Khaw, H.L. 2010. Quantitative genetic basis of fatty acid composition in the GIFT strain of Nile tilapia (Oreochromis niloticus) selected for high growth. Aquaculture, 309: 66-74. doi: 10.1016/j.aquaculture.2010. 08.034

Nguyen, N.H., Ponzoni, R.W., Chandrasoma, J., Herath, H.M.V.K.P.B. \& Wathurawadu, K. 2011. GIFT tilapia culture raise efficiency in Sri Lanka. Global Aquaculture Advocate. Retrieved from https://www.aquaculturealliance.org/advocate

Ochang, S.N. 2011. Effect of replacing cod liver oil with soybean oil as dietary lipid on carcass composition, haematology and sensory properties of Nile tilapia Oreochromis niloticus. International Aquatic Research, 3: 71-77.

Osibona, A.O. 2011. Comparative study of proximate composition, amino and fatty acids of some economically important fish species in Lagos, Nigeria. African Journal of Food Science, 5(10): 581-588.
Ponzoni, R.W., Hamzah, A., Saadiah, T. \& Kamaruzzaman, N. 2005. Genetic parameters of production and response to selection for live weight in GIFT strain of Nile tilapia (Oreochromis niloticus). Aquaculture 247(1-4): 203-210. doi: 10.1016/j.aquaculture.2005.02. 020

Ponzoni, R.W., Nguyen, H., Khaw, H., Kamaruzzaman, N., Hamzah, A. \& Abu Bakar, K. 2008. Genetic improvement of Nile tilapia (Oreochromis niloticus) present and future. In: Proceedings of 8th International Symposium on Tilapia in Aquaculture. H. Elghobashy, K. Fitzsimmons, \& A.S. Diab (Eds.). (p. 33-52). Cairo, Egypt.

Popma, T. \& Masser, M. (1999). Tilapia life history and biology. Stoneville, MS, USA: Southern Regional Aquaculture Center (SRAC) Publication No. 283.

Qiang, J., Yang, H., Wang, H., Kpundeh, M.D. \& Xu, P. 2012. Growth and IGF-I response of juvenile Nile tilapia (Oreochromis niloticus) to changes in water temperature and dietary protein level. Journal of Thermal Biology, 37(8): 686-695. doi: $10.1016 /$ j.jtherbio.2012.07.009

Ridha, M.T. 2014. Preliminary observations on growth and survival of Oreochromis spilurus $\mathrm{x}$ GIFT Oreochromis niloticus F1 reciprocal hybrids in fresh and seawater. Aquaculture Research, 45(3): 528-536. doi: 10.1111/j.13652109.2012.03256.x

Saito, H., Yamashiro, R., Alsalvar, C. \& Konno, T. 1999. Influence of diet on fatty acids of three subtropical fish, subfamily caesioninae (Caesio diagrama and $C$. tile) and family siganidae (Siganus canaliculatus). Lipids, 34(10): 10731082. doi: 10.1007/s11745-999-0459-4

Sardet, C. 2015. Plankton: Wonders of the drifting world. Chicago, Illinois, United States: The University of Chigaco Press. pp 224.

Simopoulos, A.P. 2002. The importance of ratio of omega-6/omega-3 essential fatty acids.Biomed Pharmacother, 56(8): 365-379.

Toppe, J., Abreksten, S., Hope, B. \& Aksnes, A. 2006. Chemical composition, mineral content and amino acid and lipid profiles in bones from various fish Species. Comparative Biochemistry and Physiology, 146(3): 395-401. doi: 10.1016/ j.cbpb.2006.11.020

Zenebe, T., Ahlgren, G., Gustafsson, I.B. \& Boberg, M. 1998. Fatty acid and lipid content of Oreochromis niloticus L. in Ethiopian lakes dietary effects of phytoplankton. Ecology of Freshwater Fish, 7(3): 146-158. doi: 10.1111/ j.1600-0633.1998.tb00181. 